\title{
RING STABIL BERHINGGA
}

\author{
Samsul Arifin \\ Program Studi Pendidikan Matematika, STKIP Surya, Tangerang \\ Email: samsul.arifin@stkipsurya.ac.id
}

\begin{abstract}
Dalam tulisan ini akan dibahas mengenai karakteristik ring dengan sifat stabil berhingga, motivasi dan sifat-sifatnya. Akan dibahas juga mengenai sifat stabil berhingga kuat kanan yang akan membantu dalam memahami sifat stabil berhingga, beserta sifat-sifatnya, dan tidak lupa akan dikaji juga kaitan antara keduanya.
\end{abstract}

Kata kunci: stably finite, right strong stably finite, Dedekind finite

\section{ABSTRACT}

In this paper, we will discuss about the characterization of stably finite rings and their properties. We will also discuss about right strong stably finite rings and their relationship, and also its characterization.

Keywords: stably finite, right strong stably finite, Dedekind finite

\section{PENDAHULUAN}

Perlu diasumsikan sebelumnya di sini bahwa setiap ring bersifat asosiatif dengan $1 \neq 0$, dan setiap modulnya adalah modul unital. Berdasarkan [6], $\mathrm{R}$ disebut ring stabil berhingga jika $M_{n}(R)$ adalah ring Dedekind finite. Di lain pihak, $\mathrm{R}$ disebut ring Dedekind finite jika untuk setiap $x, y \in R$ berlaku $x y=1 \Rightarrow y x=1$. Dalam tulisan ini akan dibahas kaitan ring stabil berhingga dengan ring stabil berhingga kuat (kanan), modul co-Hopfian lemah dan ring dengan kondisi rank kuat kanan. Modul kanan $M_{R}$ disebut modul co-Hopfian jika sebarang endomorfisma injektif dari M adalah suatu isomorfisma, dan $M_{R}$ disebut modul co-Hopfian lemah jika sebarang endomorfisma injektif $\mathrm{f}$ dari $\mathrm{M}$ adalah essensial, yaitu berlaku $f(M) \subseteq_{e} M$.

\section{Ring Stabil Berhingga}

Sebelum dijelaskan mengenai ring stabil berhingga, akan dijelaskan terlebih dahulu ring Dedekind finite karena terkait satu sama lain.

\subsection{Definisi (Ring Dedekind Finite):}

Ring R dikatakan ring yang Dedekind (directly atau von Neumann) finite jika untuk setiap $x, y \in R$ berlaku $x y=1 \Rightarrow y x=1$.

\subsection{Definisi (Stably Finite):}

Ring $R$ dikatakan ring yang stably-finite jika $M_{n}(R)$ adalah ring Dedekind Finite $\forall n \geq 1$.

\subsection{Akibat:}

Ring $R$ bersifat stably finite jika dan hanya jika ring $R$ bersifat Dedekind finite.
Sifat-sifat dari ring stabil berhingga tertuang dalam proposisi di bawah ini, dimana suatu ring stabil berhingga $R$ dapat dilihat dari sisi jumlahan langsung $R$-modul bebasnya dengan $R$ modul lain, epimorfisma $R$-modul bebas ke dirinya sendiri dan sifat Dedekind finite.

\subsection{Proposisi:}

Pernyataan-pernyataan di bawah ini ekuivalen:

(i) Ring $R$ adalah ring stabil berhingga.

(ii) Untuk setiap $n \in \mathbb{Z}^{+}$, jika $R^{n} \cong R^{n} \oplus K$ sebagai $R$-modul kanan maka $K=0$.

(iii) Untuk setiap $n \in \mathbb{Z}^{+}$, setiap epimorfisma $R^{n} \rightarrow R^{n}$ adalah isomorfisma.

(iv) $\operatorname{End}\left(R_{R}\right)$ adalah ring Dedekind finite.

\section{Bukti:}

$(i) \Rightarrow(i i)$

Diketahui ring $R$ memenuhi sifat stabil berhingga. Diambil sebarang $n \in \mathbb{Z}^{+}$dengan $R^{n} \cong$ $R^{n} \oplus K$ sebagai $R$-modul kanan. Karena $R^{n} \cong$ $R^{n} \oplus K$ maka ada isomorfisma modul $f: R^{n} \rightarrow$ $R^{n} \oplus K$ dengan matriks representasi $[f] \in$ $M_{m \times n}(R)$ dan $m=n+x$ untuk setiap $m$ dimensi dari $R^{n} \oplus K$ dan $x$ dimensi dari $K$. Selanjutnya ada $g: R^{n} \oplus K \rightarrow R^{n}$ dengan matriks representasi $[g] \in M_{n \times m}(R)$ sedemikian hingga $f \circ g=1_{R^{m}}$ dan $\quad g \circ f=1_{R^{n}}$. Akibatnya diperoleh $[f][g]=I_{m} \quad$ dan $\quad[g][f]=I_{m} \in M_{n}(R)$. Berdasarkan $(i), M_{n}(R)$ adalah ring Dedekind finite sehingga karena $[g][f]=I_{m} \in M_{n}(R)$ maka berlaku $[f][g]=I_{n} \in M_{n}(R)$. Di lain pihak $[f][g]=I_{m} \in M_{m}(R), m=n+x \quad$ atau $\quad I_{m}=$ $[f][g]=I_{n}$, sehingga akibatnya diperoleh $x=0$ atau $K=0$. 
$(i i) \rightarrow(i i i)$

Diambil sebarang $n \in \mathbb{Z}^{+}$dan epimorfisma $f: R^{n} \rightarrow R^{n}$.. Karena $R^{n}$ adalah $R$-modul bebas, maka $f$ split, akibatnya dapat dibentuk barisan $0 \rightarrow \operatorname{Ker}(f) \stackrel{i}{\rightarrow} R^{n} \stackrel{f}{\rightarrow} R^{n} \rightarrow 0$ dengan $R^{n}=R^{n} \oplus$ $\operatorname{Ker}(f)$, sehingga berdasarkan (ii) diperoleh $\operatorname{Ker}(f)=0$ yang artinya $f$ injektif. Karena $f$ surjektif dan injektif sekaligus, maka $f$ adalah isomorfisma.

(iii) $\Rightarrow(i)$

Diambil sebarang $n \in \mathbb{Z}^{+}$dan $X, Y \in M_{n}(R)$ dengan $\quad X Y=I_{n}$. Akibatnya diperoleh $R^{n} \stackrel{g}{\rightarrow} R^{n} \underset{\text { epi }}{\stackrel{f}{\rightarrow}} R^{n} \quad$ dengan matriks-matriks representasi $X=[f] \in M_{n}(R), Y=[g] \in M_{n}(R)$. Karena $f$ adalah epimorfisma, maka berdasarkan (iii) $f$ adalah isomorfisma, yang artinya ada $Z \in$ $M_{n}(R)$ dengan $Z X=I_{n}$. Perhatikan bahwa dengan mengalikan $Z$ dari kiri pada persamaan $X Y=I_{n}$ diperoleh:

$Z(X Y)=Z I_{n} \Leftrightarrow(Z X) Y=Z \Leftrightarrow I_{n} Y=Z \Leftrightarrow Y=Z$

Dengan demikian diperoleh $X Y=I_{n}$ yang artinya $M_{n}(R)$ ring Dedekind finite atau ring $R$ stabil berhingga.

(iii) $\Rightarrow(i v)$

Diketahui untuk setiap $n \in \mathbb{Z}^{+}$, setiap epimorfisma $R^{n} \rightarrow R^{n} \quad$ adalah isomorfisma. Diambil sebarang $a, b \in \operatorname{End}\left(R_{R}\right)$ dengan $b=$ $1_{\operatorname{End}\left(R_{R}\right)}$. Akibatnya diperoleh bahwa a surjektif, dan berdasarkan (iii) diperoleh bahwa $a$ adalah isomorfisma, sehingga terdapat $c \in \operatorname{End}\left(R_{R}\right)$ sedemikian hingga $a=1_{\operatorname{End}\left(R_{R}\right)}$. Perhatikan bahwa:

$$
c(a b)=c 1 \Leftrightarrow(c a) b=c \Leftrightarrow 1 b=c \Leftrightarrow b=c,
$$

sehingga dapat diperoleh $b a=1$, dan terbukti bahwa $\operatorname{End}\left(R_{R}\right)$ adalah ring Dedekind finite.

(iv) $\Rightarrow(i i i)$

Diketahui End $\left(R_{R}\right)$ adalah ring Dedekind finite. Diambil sebarang $n \in \mathbb{Z}^{+}$dan epimorfisma $f: R^{n} \rightarrow R^{n}$. Karena $R^{n}$ adalah $R$-modul bebas maka $f$ split. Jadi, terdapat $g: R^{n} \rightarrow R^{n}$ dengan $f$ 。 $g=1_{R} n$. Dari sini sudah bisa dikatakan bahwa $f, g \in E$, dan berdasarkan (iv), dapat diperoleh $g \circ f=1_{R}$. Dengan demikian terbukti bahwa $f$ adalah suatu isomorfosma.

\subsection{Contoh}

1. Ring komutatif memiliki sifat stabil berhingga, karena setiap ring komutatif merupakan ring Dedekind finte. Berdasarkan Akibat 2.3 di atas, diperoleh bahwa setiap ring komutatif adalah ring stabil berhingga.

2. Dalam [1], dijelaskan bahwa ring Noetherian adalah ring stabil berhingga, dengan skema pembuktian sebagai berikut:

$R$ noetherian
$\Downarrow$
$\left(R^{n}\right)_{R}$ noetherian
$\Downarrow$
setiap epimorfisma $f: R^{n} \rightarrow R^{n}$ adalah isomorfisma
$\mathbb{\Downarrow}$
$R$ stabil berhingga

Perhatikan kembali bahwa jika $g: R \rightarrow S$ adalah suatu homomorfisma ring dengan ring $S$ bersifat stabil berhingga, maka belum tentu ring $R$ juga merupakan ring stabil berhingga. Berikut merupakan syarat pemetaan di atas agar berlaku untuk sifat stabil berhingga, yang dijelaskan dalam teorema di bawah ini.

\subsection{Teorema:}

Diberikan $R$ adalah subring $S$. Jika ring $S$ adalah bersifat stabil berhingga maka $R$ juga bersifat stabil berhingga.

\section{Bukti:}

Karena $R$ adalah subring $S$ maka ada pemetaan embedding $g: R \rightarrow S$. Selanjutnya, dengan $R=S=g(R)$, maka elemen identitas $e$ di ring $R$ adalah elemen idempoten di ring $S$, dengan elemen idempoten komplemen $f=1-e$ yang memenuhi $\quad R f=f R=0$. Kemudian diambil sebarang $A, B \in M_{n}(R)$ dengan $A B=e I_{n}$. Sebelumnya perhatikan bahwa

$$
\begin{aligned}
\forall\left(A+F I_{n}\right),\left(B+f I_{n}\right) \in M_{n} & (S) \text { berlaku: } \\
\left(A+f I_{n}\right)\left(B+f I_{n}\right) & =A B+f^{2} I_{n} \\
& =e I_{n}+f I_{n} \\
& =(e+f) I_{n} \\
& =I_{n}
\end{aligned}
$$

Karena diketahui bahwa ring $S$ adalah ring stabil berhingga, maka berlaku juga:

$$
I_{n}=\left(B+f I_{n}\right)\left(A+f I_{n}\right)=B A+f I_{n}
$$

sehingga diperoleh $B A=I_{n}-f I_{n}=(1-$ e) $I_{n}=e I_{n}$. Terbukti bahwa $M_{n}(R)$ adalah ring Dedekind-finite atau dengan kata lain $R$ adalah ring stabil berhingga. Dengan demikian terbukti bahwa jika $R$ adalah subring $S$ dengan $S$ adalah ring stabil berhingga, maka ring $R$ juga merupakan ring stabil berhingga.

Selanjutnya, untuk suatu ideal $I$ di $\operatorname{ring} R$, jika ring $R$ adalah ring stabil berhingga maka belum tentu ring $R / I$ adalah ring stabil berhingga. 
Berikut adalah syarat bagi idealnya agar hal tersebut berlaku, yang dijelaskan dalam teorema di bawah ini.

\subsection{Teorema:}

Diberikan ideal $I \subseteq \operatorname{rad}(R)$. Ring $R$ adalah ring stabil behingga jika dan hanya jika ring $R / I$ adalah ring stabil berhingga.

\section{Bukti:}

Karena ring $R$ adalah ring stabil berhingga, maka $M_{n}(R)$ adalah ring Dedekind finite. Berdasarkan [6], diperoleh bahwa $S$ adalah ring Dedekind finite jika dan hanya jika $\bar{S}=S / J$ ring Dedekind finite. Untuk ring $R$ yang diberikan dan sebarang $n \geq 1$, jika dimisalkan $S=M_{n}(R)$ maka diperoleh:

$$
\begin{gathered}
J=M_{n}(I) \subseteq M_{n}(\operatorname{rad}(R))=\operatorname{rad}\left(M_{n}(R)\right)= \\
\operatorname{rad}(S), \\
\operatorname{dan} \\
S / J=M_{n}(R) / M_{n}(I) \cong M_{n}(R / I)
\end{gathered}
$$

Dari sini akan diperoleh bahwa ring $S=$ $M_{n}(R)$ adalah ring Dedekind finite jika dan hanya jika $S / J \cong M_{n}(R / I)$ ring Dedekind finite. Karena ini berlaku untuk setiap $n \in \mathbb{Z}^{+}$, maka $R / I$ adalah ring stabil berhingga. Dengan demikian terbukti bahwa untuk suatu ideal $I \in \operatorname{rad}(R)$, berlaku $R$ adalah ring stabil berhingga jika dan hanya jika $R / I$ ring stabil berhingga.

\subsection{Akibat:}

Diberikan $\prod_{i \in I} R_{i}$ adalah hasil kali langsung dari $R_{i}$. $\prod_{i \in I} R_{i}$ adalah ring stabil berhingga jika dan hanya jika $R_{i}$ untuk setiap $i \in I$ adalah ring stabil berhingga.

\section{Bukti:}

$\Rightarrow$ Diketahui $\prod_{i \in I} R_{i}$ adalah ring stabil berhingga. Karena ada pemetaan embedding $\varepsilon: R_{i} \rightarrow \prod_{i \in I} R_{i}$ maka berlaku $R_{i}$ juga merupakan ring stabil berhingga. Dengan demikian terbukti bahwa jika $\prod_{i \in I} R_{i}$ adalah ring stabil berhingga, maka $R_{i}$ juga merupakan ring stabil berhingga.

$\Leftarrow$ Diketahui $R_{i}$ adalah ring stabil berhingga untuk setiap $i \in \mathbb{Z}^{+}$. Berdasarkan [6], diperoleh bahwa untuk setiap $n \in \mathbb{Z}^{+}, M_{n}\left(R_{i}\right)$ adalah ring stabil berhingga untuk setiap $i \in \mathbb{Z}^{+}$. Akibatnya diperoleh bahwa $M_{n}\left(R_{i}\right)$ adalah ring Dedekind finite. Selanjutnya perhatikan bahwa untuk sebarang

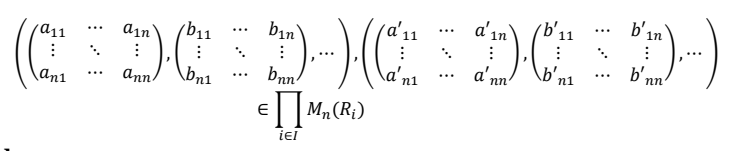

dengan

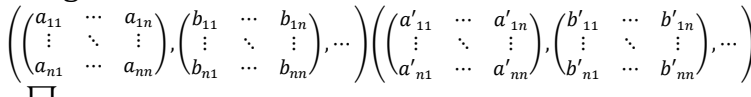

$\epsilon \prod_{i} L_{i}$

berlaku:

$$
\begin{aligned}
\left(\begin{array}{ccc}
a_{11} & \cdots & a_{1 n} \\
\vdots & \ddots & \vdots \\
a_{n 1} & \cdots & a_{n n}
\end{array}\right)\left(\begin{array}{ccc}
b_{11} & \cdots & b_{1 n} \\
\vdots & \ddots & \vdots \\
b_{n 1} & \cdots & b_{n n}
\end{array}\right)=I_{i} \\
\quad=\left(\begin{array}{ccc}
b_{11} & \cdots & b_{1 n} \\
\vdots & \ddots & \vdots \\
b_{n 1} & \cdots & b_{n n}
\end{array}\right)\left(\begin{array}{ccc}
a_{11} & \cdots & a_{1 n} \\
\vdots & \ddots & \vdots \\
a_{n 1} & \cdots & a_{n n}
\end{array}\right)
\end{aligned}
$$

untuk setiap

$$
\left(\begin{array}{ccc}
a_{11} & \cdots & a_{1 n} \\
\vdots & \ddots & \vdots \\
a_{n 1} & \cdots & a_{n n}
\end{array}\right)\left(\begin{array}{ccc}
b_{11} & \cdots & b_{1 n} \\
\vdots & \ddots & \vdots \\
b_{n 1} & \cdots & b_{n n}
\end{array}\right) \in M_{n}\left(R_{i}\right),
$$

sehingga pasti berlaku

$\left(\left(\begin{array}{lll}a^{\prime}{ }_{11} & \ldots & a_{1 n} \\ \vdots & \ddots & \vdots \\ a_{n 1}^{\prime} & \cdots & a_{n n}\end{array}\right),\left(\begin{array}{lll}b_{11}^{\prime} & \ldots & b_{1 n}^{\prime} \\ \vdots & \ddots & \vdots \\ b_{n 1}^{\prime} & \cdots & b_{n n}^{\prime}\end{array}\right), \ldots\right)\left(\left(\begin{array}{lll}a_{11} & \ldots & a_{1 n} \\ \vdots & \ddots & \vdots \\ a_{n 1} & \cdots & a_{m m}\end{array}\right),\left(\begin{array}{lll}b_{11} & \ldots & b_{1 n} \\ \vdots & \ddots & \vdots \\ b_{n 1} & \cdots & b_{n n}\end{array}\right), \ldots\right)$

$=\left(\left(\begin{array}{lll}a_{11}^{\prime} & \ldots & a_{1 n} \\ \vdots & \ddots & \vdots \\ a_{n 1}^{\prime} & \cdots & a_{n m}\end{array}\right)\left(\begin{array}{lll}a_{11} & \ldots & a_{1 n} \\ \vdots & \ddots & \vdots \\ a_{n 1} & \cdots & a_{n n}\end{array}\right),\left(\begin{array}{lll}b^{\prime}{ }_{11} & \ldots & b^{\prime}{ }_{1 n} \\ \vdots & \ddots & \vdots \\ b_{n 1}^{\prime} & \cdots & b_{n n}^{\prime}\end{array}\right)\left(\begin{array}{lll}b_{11} & \ldots & b_{1 n} \\ \vdots & \ddots & \vdots \\ b_{n 1} & \cdots & b_{n n}\end{array}\right), \ldots\right)$

$=\left(\left(\begin{array}{lll}a_{11} & \ldots & a_{1 n} \\ \vdots & \ddots & \vdots \\ a_{n 1} & \cdots & a_{n n}\end{array}\right)\left(\begin{array}{lll}a^{\prime} & \ldots & a_{1 n} \\ \vdots & \ddots & \vdots \\ a_{n 1}^{\prime} & \cdots & a_{n n}\end{array}\right),\left(\begin{array}{lll}b_{11} & \ldots & b_{1 n} \\ \vdots & \ddots & \vdots \\ b_{n 1} & \cdots & b_{n n}\end{array}\right)\left(\begin{array}{lll}b_{11}^{\prime} & \ldots & b^{\prime}{ }_{1 n} \\ \vdots & \ddots & \vdots \\ b_{n 1}^{\prime} & \cdots & b_{n n}^{\prime}\end{array}\right), \ldots\right)$

$=\prod_{i} I_{i}$

yang artinya bahwa $\prod_{i \in I} M_{n}(R i)$ adalah ring Dedekind finite. Dari sini diperoleh bahwa $M_{n}\left(\prod_{i \in I} R_{i}\right)$ juga merupakan ring Dedekind finite, karena $M_{n}\left(\prod_{i \in I} R_{i}\right) \cong \prod_{i \in I} M_{n}\left(R_{i}\right)$ dengan

$\left(\begin{array}{ccc}\left(a_{11}, b_{11}, \ldots\right) & \ldots & \left(a_{1 n}, b_{1 n}, \ldots\right) \\ \vdots & \ddots & \vdots \\ \left(a_{n 1}, b_{n 1}, \ldots\right) & \ldots & \left(a_{n n}, b_{n n}, \ldots\right)\end{array}\right) \mapsto$
$\left(\left(\begin{array}{ccc}a_{11} & \ldots & a_{1 n} \\ \vdots & \ddots & \vdots \\ a_{n 1} & \ldots & a_{n n}\end{array}\right),\left(\begin{array}{ccc}b_{11} & \ldots & b_{1 n} \\ \vdots & \ddots & \vdots \\ b_{n 1} & \ldots & b_{n n}\end{array}\right), \ldots\right)$

untuk setiap $a_{i} \in A_{i}$, yang artinya bahwa $M_{n}\left(\prod_{i \in I} R_{i}\right)$ juga merupakan ring stabil berhingga. Oleh karena itu diperoleh bahwa $\prod_{i \in I} R_{i}$ adalah ring stabil berhingga. Dengan demikian terbukti bahwa jika $R_{i}$ adalah ring stabil berhingga maka $\prod_{i \in I} R_{i}$ juga merupakan ring stabil berhingga.

Sebelumnya akan dijelaskan proses konstruksi dari ring matriks triangular formal. Dari ring $A, B,(A, B)$-bimodul $M$ dapat dibentuk ring:

$$
T=\left(\begin{array}{cc}
A & 0 \\
M & B
\end{array}\right)=\left\{\left(\begin{array}{cc}
a & 0 \\
m & b
\end{array}\right) \mid a \in A, b \in B, m \in M\right\}
$$

yang disebut ring matriks triangular formal. Operasi penjumlahan dan pergandaan pada ring $T$ adalah sebagai berikut: 
a) $\left(\begin{array}{ll}a & 0 \\ m & b\end{array}\right)+\left(\begin{array}{cc}a^{\prime} & 0 \\ m^{\prime} & b^{\prime}\end{array}\right)=$ $\left(\begin{array}{cc}a+a^{\prime} & 0 \\ m+m^{\prime} & b+b^{\prime}\end{array}\right)$

b) $\left(\begin{array}{cc}a & 0 \\ m & b\end{array}\right)\left(\begin{array}{cc}a^{\prime} & 0 \\ m^{\prime} & b^{\prime}\end{array}\right)=$

$$
\left(\begin{array}{cc}
a a^{\prime} & 0 \\
m a^{\prime}+b m^{\prime} & b b^{\prime}
\end{array}\right)
$$

untuk setiap $\left(\begin{array}{cc}a & 0 \\ m & b\end{array}\right),\left(\begin{array}{cc}a^{\prime} & 0 \\ m^{\prime} & b^{\prime}\end{array}\right) \in T$. Kemudian jika diberikan ring-ring $\mathrm{A}$ dan $\mathrm{B}$, suatu grup abelian $\mathrm{M}$ disebut $(A, B)$-bimodul, dinotasikan ${ }_{A} M_{b}$, jika $\mathrm{M}$ adalah A-modul kiri dan B-modul kanan serta berlaku $(a m) b=a(m b)$ untuk setiap $a \in A, m \in M$, dan $b \in B$.

Berikut adalah kaitan antara ring stabil berhingga dan ring matriks triangular formal.

\subsection{Proposisi}

Diberikan ring $A, B$, dan ${ }_{B} M_{A}$ adalah $(B, A)$ bimodul. Ring $T=\left(\begin{array}{cc}A & 0 \\ M & B\end{array}\right)$ adalah ring stabil berhingga jika dan hanya jika ring A dan B adalah ring stabil berhingga.

\section{Bukti:}

$\Rightarrow$ Diketahui ring $T=\left(\begin{array}{cc}A & 0 \\ M & B\end{array}\right)$ adalah ring stabil berhingga. Perhatikan bahwa ada pemetaan embedding $\varepsilon_{1}: A \rightarrow\left(\begin{array}{cc}A & 0 \\ M & B\end{array}\right)$ dengan $\left(\begin{array}{ll}a & 0 \\ 0 & 0\end{array}\right) \mapsto$ $\left(\begin{array}{cc}a & 0 \\ m & b\end{array}\right)$ untuk setiap $\left(\begin{array}{cc}a & 0 \\ 0 & 0\end{array}\right) \in\left(\begin{array}{cc}A & 0 \\ 0 & 0\end{array}\right) \cong A$, dan juga ada embedding $\varepsilon_{2}: B \rightarrow\left(\begin{array}{cc}A & 0 \\ M & B\end{array}\right)$ dengan $\left(\begin{array}{cc}0 & 0 \\ 0 & b\end{array}\right) \mapsto\left(\begin{array}{cc}a & 0 \\ m & b\end{array}\right)$ untuk setiap $\left(\begin{array}{cc}0 & 0 \\ 0 & b\end{array}\right) \in$ $\left(\begin{array}{ll}0 & 0 \\ 0 & B\end{array}\right) \cong B$.

Akibatnya, karena $\operatorname{ring} T=\left(\begin{array}{cc}A & 0 \\ M & B\end{array}\right)$ adalah ring stabil berhingga maka berakibat masing-masing ring $A$ dan $B$ juga merupakan ring stabil berhingga. Dengan demikian terbukti bahwa jika ring $T=\left(\begin{array}{cc}A & 0 \\ M & B\end{array}\right)$ adalah ring stabil berhingga maka ring $A$ dan $B$ juga merupakan ring stabil berhingga.

$\Leftarrow \quad$ Diketahui ring $A$ dan $B$ adalah ring stabil berhingga. Perhatikan kembali bahwa ideal $I=$ $\left(\begin{array}{cc}0 & 0 \\ M & 0\end{array}\right) \subseteq T$ adalah ideal nilpotent dan $T / I \cong$ $A \times B$. Selanjutnya, jika diberikan $n \in \mathbb{Z}^{+}$sebarang dan dinotasikan ring $X_{n}=M_{n}(X)$, maka akan diperoleh:

$$
\begin{aligned}
T_{n} / I_{n} & =M_{n}(T) / M_{n}(I) \\
& =M_{n}\left(\left(\begin{array}{cc}
A & 0 \\
M & B
\end{array}\right)\right) / M_{n}\left(\left(\begin{array}{cc}
0 & 0 \\
M & 0
\end{array}\right)\right) \\
& \cong M_{n}\left(\left(\begin{array}{cc}
A & 0 \\
M & B
\end{array}\right) /\left(\begin{array}{cc}
0 & 0 \\
M & 0
\end{array}\right)\right) \\
& =M_{n}(T / I) \\
& =(T / I)_{n} \\
& \cong(A \times B)_{n}
\end{aligned}
$$

Perhatikan bahwa ring $A$ dan $B$ adalah ring stabil berhingga jika dan hanya jika ring $A \times B$ adalah ring stabil berhingga, sehingga ring

$$
\begin{aligned}
M_{n}(A \times B) & =(A \times B)_{n} \\
& \cong T_{n} / I_{n} \\
& =M_{n}\left(\left(\begin{array}{cc}
A & 0 \\
M & B
\end{array}\right)\right) / M_{n}\left(\left(\begin{array}{cc}
0 & 0 \\
M & 0
\end{array}\right)\right)
\end{aligned}
$$

adalah ring Dedekind finte. Karena $I_{n}=M_{n}(I)$ adalah ideal nilpotent maka diperoleh bahwa $T_{n}=$ $M_{n}\left(\begin{array}{cc}A & 0 \\ M & B\end{array}\right)$ adalah ring Dedekind finte, sehingga diperoleh bahwa $\operatorname{ring} T=M_{n}\left(\begin{array}{cc}A & 0 \\ M & B\end{array}\right)$ adalah ring stabil berhingga. Dengan demikian terbukti bahwa jika $A$ dan $B$ adalah ring stabil berhingga maka ring $T=\left(\begin{array}{cc}A & 0 \\ M & B\end{array}\right)$ juga merupakan ring stabil berhingga.

Dalam [1], dijelaskan juga karakteristik lain dari ring stabil berhingga, yang termuat dalam skema berikut:

$$
\begin{aligned}
& M_{n}(R) \text { is "SB" } \quad \Leftrightarrow \quad R \text { is "SB" } \quad \Leftrightarrow \quad R[x] \text { is "SB" } \\
& \mathbb{1} \\
& R[[x]] \text { is "SB" }
\end{aligned}
$$

dengan $\mathrm{SB}=$ Stabil Berhingga, serta untuk sebarang ring tak nol berlaku:

$$
\text { stabil berhingga } \Rightarrow \text { kondisi rank } \Rightarrow \text { IBN. }
$$

\section{MODUL CO-HOPFIAN LEMAH DAN RING STABIL BERHINGGA KUAT KANAN}

Sebelum dijelaskan mengenai ring stabil berhingga kuat kanan, akan dijelaskan terlebih dahulu mengenai modul co-Hopfian (lemah) karena saling berkaitan satu sama lain. 


\subsection{Definisi (Modul co-Hopfian (Lemah)):}

Diberikan ring $R$ dan $M_{R}$ adalah modul kanan. $M$ disebut modul co-Hopfian jika sebarang endomorfisma injektif dari $M$ adalah suatu isomorfisma, dan $M$ disebut modul co-Hopfian lemah jika sebarang endomorfisma injektiff dari $M$ adalah essensial, yaitu berlaku $f(M) \subseteq_{e} M$.

Dalam [4] dijelaskan, ada teorema yang menyatakan bahwa definisi modul co-Hopfian lemah bisa dinyatakan dalam enam kalimat, yaitu sebagai berikut:

\subsection{Teorema}

Pernyataan-pernyataan berikut ekuivalen untuk suatu R-modul kanan $M$ :

(1) $M_{R}$ adalah modul co-Hopfian lemah.

(2) Untuk sebarang R-modul kanan $N$, jika ada $R$ monomorfisma $M \oplus N \rightarrow M$ maka $N=0$.

(2') Untuk sebarang $R$-modul kanan $N$, jika $M \oplus$ $N \rightarrow M$ adalah monomorfisma essensial maka $N=0$.

(3) Madalah modul Dedekind finite dan image dari sebarang endomorfisma injektif dari M adalah essensial atau direct summand sejati.

(4) Terdapat suatu submodul essensial invariant penuh yang bersifat co-Hopfian lemah.

(5) Endomorfisma injektif dari $M_{R}$ memetakan submodul-submodul essesnsial ke submodulsubmodul essensial.

(6) Image inverse dari sebarang submodul tak nol dari sebarang endomorfisma injektif dari $M$ adalah tak nol.

Berikut adalah sifat-sifat dari modul co-Hopfian lemah:

\subsection{Akibat:}

Suatu direct summand dari modul co-Hopfian lemah juga merupakan modul co-Hopfian lemah.

Proposisi berikut menjelaskan kaitan antara modul co-Hopfian (lemah) dan modul Dedekind finite, yaitu sebagai berikut.

\subsection{Proposisi:}

Pernyataan-pernyataan berikut berlaku:

(1) Untuk suatu R-modul M berlaku: $M$ co-Hopfian $\Rightarrow M$ co-Hopfian lemah $\Rightarrow M$ Dedekind finite.

(2) Jika M adalah modul quasi-injektif, maka berlaku: a) M co-Hopfian $\Leftrightarrow M$ co-Hopfian lemah $\Leftrightarrow M$ Dedekind finite.

b) Jika $M$ adalah modul co-Hopfian lemah maka sebarang submodul dan sebarang direct sum berhingga yang memuat $M$ adalah modul co-Hopfian lemah.

c) Jika $N$ adalah submodul essensial invariant penuh, maka berlaku:

$N$ co-Hopfian $\Leftrightarrow$ M co-Hopfian $\Leftrightarrow E(M)$ co-Hopfian

Berikut adalah sifat-sifat modul co-Hopfian:

\subsection{Proposisi:}

Pernyataan-pernyataan berikut berlaku:

a) Jika $M_{R}$ adalah modul kanan dengan sebarang submodul co-Hopfian lemah, maka $M$ adalah modul co-Hopfian lemah.

b) Diberikan $N$ adalah submodul invariant penuh yang co-Hopfian di modul kanan $M_{R}$. Jika $M / N$ adalah modul co-Hopfian (lemah) maka $M$ modul co-Hopfian (lemah).

c) Jika submodul-submodul nonessensial di $M_{R}$ adalah submodul Noetherian, maka $M$ adalah modul co-Hopfian lemah.

Berikut adalah akibat dari proposisi di atas:

\subsection{Akibat:}

Pernyataan-pernyataan berikut berlaku:

a) Suatu modul semisederhana $M$ adalah modul co-Hopfian lemah jika dan hanya jika sebarang komponen homogen di $M$ dibangun secara berhingga.

b) Jika $M$ adalah modul Hopfian dan bersifat kondisi rantai turun, maka submodulsubmodulnya adalah co-Hopfian.

c) Jika M memiliki sifat kondisi rantai turun pada submodul-submodul non-co-Hopfiannya, maka $M$ adalah modul co-Hopfian.

Setelah dijelaskan mengenai modul coHopfian (lemah) dan sifat-sifatnya, selanjutnya akan dibahas mengenai ring stabil berhingga kuat.

\subsection{Definisi (Right Strong Stably Finite):}

Suatu ring $R$ disebut ring stabil berhingga kuat kanan jika $R_{R}^{n}$ adalah modul co-Hopfian lemah untuk setiap $n \geq 1$.

Berikut adalah karakteristik ring stabil berhingga kuat kanan. Dalam [4] dijelaskan bahwa 
ring stabil berhingga kuat kanan dapat dinyatakan dalam tiga kalimat yaitu tertuang dalam teorema berikut:

\subsection{Teorema:}

Pernyataan-pernyataan berikut ekuivalen:

(1) R adalah ring stabil berhingga kuat kanan.

(2) Untuk sebarang $n \geq 1$, jika $u_{1}, \ldots, u_{n}$ adalah elemen-elemen yang $R$-bebas linear di dalam modul bebas $R_{R}^{n}$ maka $u_{1} R+\ldots+u_{n} R$ adalah submodul essensial.

(3) Untuk sebarang $n \geq 1, M_{n}(R)$ adalah ring coHopfian kanan.

\subsection{Definisi:}

Ring $R$ dikatakan Ore kanan jika untuk setiap $a, b \in$ $R$ dengan $b$ adalah elemen regular, terdapat $c, d \in$ $R$ dengan $d$ adalah elemen regular, sehingga berlaku $a d=b c$.

Dalam [7] dijelaskan kaitan antara ring Ore kanan dan ring stabil berhingga kuat kanan, yaitu sebagai berikut:

\subsection{Teorema:}

Jika $R$ adalah ring dengan $R[x]$ adalah ring Ore kanan, maka $R$ adalah ring stabil berhingga kuat kanan.

\section{KAITAN ANTARA RING STABIL BERHINGGA DENGAN RING STABIL BERHINGGA KUAT KANAN}

Berikut adalah kaitan antara ring stabil berhingga dan ring stabil berhingga kuat kanan. Dalam [7] dijelaskan kaitan antara ring stabil berhingga, ring stabil berhingga kuat kanan, ring dengan kondisi rank kuat kanan dan ring komutatif, yaitu sebagai berikut:

$\begin{array}{lll} & S B \\ \text { u. } \operatorname{dim} R_{R}<\infty \Rightarrow & \Uparrow \\ & S B K K \\ & \Uparrow \\ & \text { Komutatif }\end{array}$

dengan SB = Stabil Berhingga, SBKK = Stabil Berhingga Kuat Kanan dan KRKK = Kondisi Rank Kuat Kanan.

\subsection{Proposisi:}

Ring komutatif $\Rightarrow$ Ring stabil berhingga kuat kanan $\Rightarrow$ Ring stabil berhingga.
Proposisi berikut menjelaskan kaitan antara ring stabil berhingga dan ring stabil berhingga kuat kanan.

\subsection{Proposisi:}

Jika ring $R$ adalah ring stabil berhingga kuat kanan, maka ring $R$ adalah ring stabil berhingga. Lebih lanjut, untuk suatu modul injektif $R_{R}$, ring $R$ adalah ring stabil berhingga kuat kanan jika dan hanya jika ring $R$ adalah ring stabil berhingga.

\section{Bukti:}

Misalkan $\mathrm{R}$ adalah ring stabil berhingga kuat kanan dan $n \in \mathbb{Z}^{+}$dengan $R^{n} \oplus K \cong R^{n}$ untuk suatu $K \in \operatorname{Mod}-R$. Berdasarkan [4, 1.1], dapat diperoleh bahwa $R^{n} \oplus K$ dapat diembeddingkan ke dalam $R^{n}$ sehingga berakibat $K=0$. Dengan menggunakan $[6,1.7]$, maka dapat dibuktikan bahwa $\mathrm{R}$ adalah ring stabil berhingga. Sebaliknya, misalkan $R_{R}$ adalah modul injektif dan $\mathrm{R}$ adalah ring stabil berhingga. Dengan menggunakan [4, 1.4], maka diperoleh bahwa $R_{R}$ adalah modul co-Hopfian, sehingga berdasarkan [4, 1.5(i)], diperoleh bahwa $R_{R}^{n}$ adalah modul coHopfian, $\left(\forall n \in \mathbb{Z}^{+}\right)$. Oleh karena itu terbukti bahwa R adalah ring stabil berhingga kuat kanan.

Proposisi berikut menjelaskan kaitan antara ring stabil berhingga kuat kanan dan ring dengan kondisi rank kuat kanan.

\subsection{Proposisi:}

Jika $R$ adalah ring stabil berhingga kuat kanan, maka ring $R$ bersifat kondisi rank kuat kanan. Lebih lanjut, untuk suatu daerah integral $R, R$ adalah ring stabil berhingga kuat kanan jika dan hanya jika ring $R$ bersifat kondisi rank kuat kanan.

\section{Bukti:}

Diasumsikan bahwa $0 \rightarrow R^{m} \rightarrow R^{n}$ adalah barisan eksak di dalam $\operatorname{Mod}-R$ dengan $m>n$. Dari sini dapat diperoleh bahwa $R^{n} \oplus R^{m-n} \cong R^{m}$ dapat diembeddingkan ke dalam $R^{n}$. Karena $R^{n}$ diasumsikan adalah modul co-Hopfian lemah, maka diperoleh kontradiksi dengan $R^{m-n}=0$. Oleh karena itu terbukti bahwa ring $\mathrm{R}$ bersifat kondisi rank kuat kanan. Sebaliknya, dari $[6,1.32]$ diperoleh bahwa untuk suatu daerah integral, sifat kondisi rank kuat kanan ekuivalen dengan sifat Ore kanan, sehingga menjadi seragam. Ada cara lain untuk untuk membuktikan hal ini yaitu: misalkan $\mathrm{R}$ adalah daerah integral dengan sifat kondisi rank kuat kanan dan $N \subseteq R^{k}$ sedemikian hingga $N \cong R_{R}{ }^{k}$. Jika $\mathrm{N}$ bukan submodul esensial, maka terdapat suatu submodul tak nol L di modul $R^{k}$ dengan $N \cap L=0$. Untuk sebarang elemen tak 
nol $l \in L$ berlaku $l R \cong R$ karena $\mathrm{R}$ adalah daerah integral, sehingga berlaku

$$
R^{k} \oplus R \cong N \oplus l R \subseteq R^{k} .
$$

Hal ini kontradiksi dengan $\mathrm{R}$ yang bersifat kondisi rank kuat kanan. Oleh karena itu, pastilah $\mathrm{N}$ adalah submodul esensial sehingga $\mathrm{R}$ adalah ring stabil berhingga kuat kanan.

Selanjutnya akan dibahas mengenai sifatsifat ring stabil berhingga kuat kanan. Proposisi berikut menjelaskan kaitan ring stabil berhingga kuat kanan $\mathrm{R}$ dan vektor-vektor yang R-bebas linear pada modul bebas $R_{R}^{n}$.

\subsection{Proposisi:}

$R$ adalah ring stabil berhingga kuat kanan jika dan hanya jika $\forall n \geq 1$, jika $u_{1}, u_{2}, \ldots, u_{n}$ vektor-vektor yang $R$-bebas linear di modul $R_{R}^{n}$, maka $u_{1} R+$ $u_{2} R+\ldots+u_{n} R$ adalah suatu submodul esensial di $\operatorname{modul} R_{R^{n}}^{n}$

\section{Bukti:}

Misalkan $\mathrm{R}$ adalah ring stabil berhingga kuat kanan dan $u_{1}, u_{2}, \ldots, u_{n}$ adalah vektor-vektor yang R-bebas linear di modul $R_{R}^{n}$. Pemetaan $f: R^{n} \rightarrow R^{n} \quad$ dengan $\quad f\left(r_{1}, r_{2}, \ldots, r_{n}\right)=u_{1} r_{1}+$ $u_{2} r_{2}+\ldots u_{n} r_{n}$ adalah suatu R-monomorfisma kanan dengan $\operatorname{Im}(f)=u_{1} R+u_{2} R+\ldots u_{n} R$. Karena $R^{n}$ adalah modul co-Hopfian maka diperoleh $\operatorname{Im}(f) \subseteq_{e} R_{R}^{n}$. Sebaliknya, misalkan $\mathrm{g}$ adalah endomorfisma injektif dari $R_{R}^{n}$ dengan $g\left(e_{i}\right)=u_{i}$ di mana $e_{i}=(0, \ldots, 1,0, \ldots, 0)$. Karena g injektif maka jika $u_{1} r_{1}+u_{2} r_{2}+\ldots u_{n} r_{n}=0$ akan berakibat $r_{1}=r_{2}=\ldots=r_{n}=0$. Oleh karena itu diperoleh bahwa $u_{1}, u_{2}, \ldots, u_{n}$ adalah vektor-vektor yang $\mathrm{R}$-bebas linear sehingga berdasarkan asumsi yang digunakan, $\operatorname{Im}(g)=$ $u_{1} R+u_{2} R+\ldots+u_{n} R$ adalah submodul esensial.

\subsection{Teorema:}

Setiap ring komutatif adalah ring stabil berhingga kuat.

\section{Bukti:}

Kita gunakan Proposisi 4.4 di atas pada kasus suatu ring komutatif R. Misalkan $u_{1}, u_{2}, \ldots, u_{n}$ adalah vektor-vektor yang $\mathrm{R}$-bebas linear di modul $R_{R}^{n}$ dan himpunan $\mathrm{I}=u_{1} R+$ $u_{2} R+\ldots u_{n} R$. Akan ditunjukkan bahwa untuk sebarang vector tak nol $u_{n+1} \in R^{n}$ berlaku $I \cap$ $u_{n+1} R \neq 0$. Tulis

$$
u_{j}=\sum_{i} e_{i} a_{i j}(j=1, \ldots, n+1 \operatorname{dan} i=1, \ldots, n)
$$

dengan $a_{i j} \in R$, kemudian notasikan $\mathrm{S}$ sebagai subring dari $\mathrm{R}$ yang dibangun oleh elemen-elemen $a_{i j} \in R$ dan $1_{R}$. Berdasarakan Teorema Basis Hilbert, $\mathrm{S}$ adalah ring Noetherian, sehingga $S$ memiliki dimensi seragam yang berhingga. Akibatnya $\mathrm{S}$ adalah ring stabil berhingga kuat. Perhatikan bahwa $u_{1}, u_{2}, \ldots, u_{n+1} \in S^{n}$ dan $u_{1}, u_{2}, \ldots, u_{n}$ adalah $S$ bebas linear. Oleh karena itu berlaku $\left(u_{1} S+\right.$ $\left.u_{2} S+\ldots u_{n} S\right) \cap u_{n+1} S \neq 0$ dan berdasarkan Proposisi di atas maka berlaku $I \cap u_{n+1} R \neq 0$ atau $I \subseteq_{e} R^{n}$.

Terdapat kaitan yang sangat erat antara ring stabil berhingga kuat kanan, modul coHopfian lemah, dan ring yang memenuhi kondisi rank kuat kanan. Hal tersebut dijelaskan dalam [4], yaitu dalam proposisi berikut:

\subsection{Proposisi:}

Diberikan R adalah daerah integral. Pernyataanpernyataan berikut ekuivalen:

(1) $R_{R}$ adalah modul co-Hopfian lemah

(2) R adalah ring stabil berhingga kuat kanan

(3) Ring R memenuhi kondisi rank kuat kanan

(4) Sebarang dua elemen di ring $R$ tidak R-bebas linear kanan

\section{REFERENSI:}

[1] Arifin, S., 2011, Characteristic of IBN, Rank Condition and Stably Finite Rings, Proc. Of The Seams-GMU Conference, 6, 223-232.

[2] Breaz, S., Calugareanu, G., and Schultz, P., 1991, Modules With Dedekind Finite Endomorphism Rings, Babes Bolyai University, 1-13.

[3] Haghany, A., Varadarajan, K., 2002, IBN And Related Properties For Rings, Acta Mathematica Hungarica, 94, 251-261.

[4] Haghany, A., Vedadi, M.R., 2001, Modules whose Injective Endomorphisms Are Essential, Journal of Algebra, 243, 765-779

[5] Lam, T. Y., Exercises in Modules and Rings, 2007, Springer Verlag, New York.

[6] Lam, T. Y., Lectures On Modules And Rings, 1999, Springer Verlag, New York.

[7] Vedadi, M.R., 2009, Strong Stably Finite Rings and Some Extensions, Acta Math. Univ. Comenianae, 1, 137-144 